\title{
Preoperative embolisation, transpedicular decompression and posterior stabilisation for metastatic disease of the thoracic spine causing paraplegia
}

\author{
S Y Bhojraj MS, ${ }^{1}$ A V Dandawate $M S,{ }^{2}$ R Ramakantan $\mathrm{MD}^{3}$ \\ ${ }^{1}$ Associate Professor of Orthopaedics, ${ }^{2}$ Lecturer in Orthopaedics, ${ }^{3}$ Professor of \\ Radiology, Seth GS Medical College and KEM Hospital, Parel, Bombay 400012, India.
}

\begin{abstract}
During a brief period from March 1988 to January 1990 we were faced with 13 patients with malignant vertebral neoplasms (metastasis) of the thoracic spine. Nine of these had progressive extradural spinal cord compression with motor, sensory and sphincter involvement of varying degrees and duration. After proper evaluation these 9 cases were aggressively managed by preoperative embolisation of the tumour, transpedicular decompression and a same stage posterior metallic fixation. The immediate results were encouraging, with 2 patients showing total recovery and 3 showing partial recovery. All of the 9 operated cases were pain free postoperatively and could sit up unaided and be easily transferred to the Cancer Institute for back up chemotherapy and radiotherapy. They also improved psychologically, and cooperated well in their subsequent rehabilitation programme.
\end{abstract}

Key words: thoracic spinal metastasis; paraplegia; preoperative embolisation; transpedicular decompression; posterior stabilisation.

\section{Introduction}

The vertebral column is a common site for metastasis. Patients with extradural tumours of the spine present with symptoms of back pain or spinal cord compression or both. It has been estimated that epidural compression of the spinal cord develops in $5 \%$ of patients with systemic cancer. ${ }^{1}$ Irreversible loss of ability to walk occurs in more than one half of these patients, a prognosis that has changed little in 20 years. ${ }^{1}$

There is considerable diversity of opinion in the literature regarding the optimal management of spinal cord compression due to intraspinal extradural metastasis. ${ }^{2}$

Radiotherapy to a localised lesion will often give excellent pain control ${ }^{3,4}$ and may help to relieve spinal cord compression in a selected group of cases. ${ }^{5-7}$ Laminectomy alone was also proposed as a means of surgical decompression. ${ }^{8,9}$ However, other studies have shown that radiotherapy alone is as effective as decompressive laminectomy followed by irradiation. ${ }^{2,10}$

Correspondence: 141, Sukrut, Veer Savarkar Road, Dadar, Bombay 400028 , India.
The recent emergence of alternatives to the above forms of treatment shows a growing awareness that more innovative approaches and combinations of treatments may offer improved functional results.

Anterior (transthoracic) decompression and stabilisation have been reported to give improved results concerning both neurological recovery and relief of pain..$^{1,11,12}$ But in many instances, because of their poor general medical condition or the degree of tumour vascularity, these patients may indicate that the operative risks with these comparatively extensive procedures would be unacceptably high. In a continued quest for a better and viable solution for this devastating problem we propose a new protocol for managing patients with malignant extradural spinal tumours (metastatic) of the thoracic spine with neurological deficit.

Our management protocol is as follows: (1) preoperative embolisation; (2) transpedicular decompression; and (3) posterior stabilisation. (2) and (3) are carried out during the same operation. 


\section{Materials and methods}

This study was conducted at the SDB Orthopaedic Centre, KEM Hospital, Bombay, India, from March 1988 to January 1990.

We treated 9 cases of malignant vertebral tumours (metastasis) of the thoracic spine: 2 males and 7 females, with ages varying between 16 and 68 years. The most common presenting features were back pain and progressive weakness of both lower limbs with bladder and bowel involvement. The back pain was local and radiating girdle type pain not relieved by rest or by analgesics, and even turning in bed was painful.

Clinical examination of the spine revealed tenderness on deep pressure in the area in which the disease process was present. Occasionally a local gibbus was present. There was limitation of spinal movements with aggravation of symptoms when the spine was actively moved.

Neurological examination revealed motor, sensory and sphincter involvement of varying degrees graded according to Frankel's grading (Table I). Preoperatively, all patients had disturbance of urinary bladder function.
Plain radiography in almost all of the cases revealed a central vertebral body lesion with a compression failure and concertina collapse with maintenance of disc space on either side, and a small paravertebral shadow.

Radio-nuclide bone scan using Technitium 99 was performed in all of these cases to demonstrate whether or not the lesion was multicentric at presentation.

Myelography demonstrated a complete extradural block corresponding to the radiological lesion in all of the cases.

Intercostal angiogram performed via the transfemoral route in all cases revealed neovascularity. There was a mild to moderate 'tumour blush' (associated with or without prominent draining veins).

Embolisation of the intercostal vessels was done with particulate gel foam suspended in a dilute contrast medium. Postembolisation intercostal angiograms revealed significant $(70-100 \%)$ reduction in the tumour vascularity with no tumour blush.

In none of the 9 patients who underwent a spinal angiogram prior to the embolisation was the anterior spinal artery, or the radiculomedullary feeders in the upper dorsal

Table 1 Patient data

\begin{tabular}{|c|c|c|c|c|c|c|c|}
\hline \multirow[t]{2}{*}{ Case no } & \multirow[t]{2}{*}{ Sex/Age } & \multirow[t]{2}{*}{ Site } & \multirow[t]{2}{*}{ Primary } & \multirow[t]{2}{*}{$\begin{array}{l}\text { Duration of } \\
\text { cord compress- } \\
\text { ion in weeks } \\
\text { (onset-surgery) }\end{array}$} & \multirow[t]{2}{*}{ Procedure } & \multicolumn{2}{|c|}{$\begin{array}{l}\text { Neurological } \\
\text { status (Frankel's } \\
\text { grades) }\end{array}$} \\
\hline & & & & & & Preop & Postop \\
\hline 1 & $\mathrm{~F} / 56$ & $\mathrm{~T} 5$ & $\begin{array}{c}\text { Breast } \\
\text { chondrosarcoma }\end{array}$ & 16 & $\mathrm{H}_{2}+\mathrm{C}_{\mathrm{M}}$ & $\mathrm{C}$ & $\mathrm{C}$ \\
\hline 2 & $\mathrm{~F} / 28$ & T5 & Breast & 6 & $\mathrm{H}_{1}+\mathrm{CR}$ & $\mathrm{C}$ & $\mathrm{C}$ \\
\hline 3 & $\mathrm{~F} / 55$ & $\mathrm{~T} 10$ & Thyroid & 4 & $\mathrm{H}_{2}+\mathrm{CR}$ & $\mathrm{C}$ & $\mathrm{E}$ \\
\hline 4 & $\mathrm{M} / 65$ & T5 & Prostate & 5 & $\mathrm{H}_{2}+\mathrm{CR}$ & A & A \\
\hline 5 & $\mathrm{M} / 68$ & $\mathrm{~T} 7-8$ & $\begin{array}{l}\text { Thyroid } \\
\text { (follicular) }\end{array}$ & 8 & $\mathrm{H}_{2}+\mathrm{CR}$ & $\mathrm{C}$ & $\mathrm{D}$ \\
\hline 6 & $F / 35$ & $\mathrm{~T} 8$ & Breast & 3 & $\mathrm{H}_{2}+\mathrm{CR}$ & A & $\mathrm{C}$ \\
\hline 7 & $\mathrm{~F} / 48$ & $\mathrm{~T} 4$ & Breast & 5 & $\mathrm{H}_{2}+\mathrm{CR}$ & A & $\mathrm{E}$ \\
\hline 8 & $F / 16$ & $\mathrm{~T} 7$ & Rhabdomyosarcoma & 16 & $\mathrm{H}_{2}+\mathrm{CR}$ & A & $\mathrm{C}$ \\
\hline 9 & $\mathrm{~F} / 63$ & T3 & Thyroid & 5 & HILL + SLW & A & A \\
\hline
\end{tabular}

$\mathrm{H}_{1}=$ single Harrington rod, $\mathrm{H}_{2}=$ bilateral Harrington rod, $\mathrm{HILL}=$ Hartshill rectangle, SLW = Sublaminar wiring, $C_{M}=$ cement,$C=$ chemotherapy, $R=$ radiotherapy.

Frankel's grades: $\mathrm{A}=$ complete paralysis, $\mathrm{B}=$ sensory preservation only, $\mathrm{C}=$ motor paralysis useless, $\mathrm{D}=$ motor paralysis useful, $\mathrm{E}=$ total recovery. 
region or the artery of Adamkiewicz in the lower dorsal spine visualised.

The percentage reduction in tumour vascularity was subjective. This depended on the number of feeders to the tumour embolised and the total number of feeders to the tumour, with consequent reduction in tumour vascularity and absence of tumour blush.

In 4 of the 9 patients the preoperative histopathological diagnosis was known (one case by a preoperative FNAC and in 3 cases the patients had a known primary tumour).

The criteria used for the selection of the patients for this management protocol were as follows:-

1 Final histopathological diagnosis. This is important as in 5 of our cases no preoperative diagnosis was known and hence surgery alone gave the clue to the final histopathological diagnosis and hence the prognosis.

2 Response of the tumour to subsequent radiotherapy and chemotherapy to control the systemic and local deposit.
3 Localisation of the spinal lesion, whether single or multiple. Multiple lesions were a contraindication to aggressive surgery.

4 Fitness for anaesthesia for the above mentioned surgical procedure (general medical condition).

5 The attitude of the patient towards his problem. The patient himself had to be keen on surgery and on obtaining relief from his back pain and neurological deficit.

For these patients our plan of action was as follows:-

1 Preoperative embolisation of the tumour (Fig 1), thereby devascularising the tumour and decreasing the intraoperative blood loss in these patients already in a compromised general medical condition. We have been successful in minimising the blood loss to an average of 1.5 litres and in restricting the operating time on an average to 3 hours.

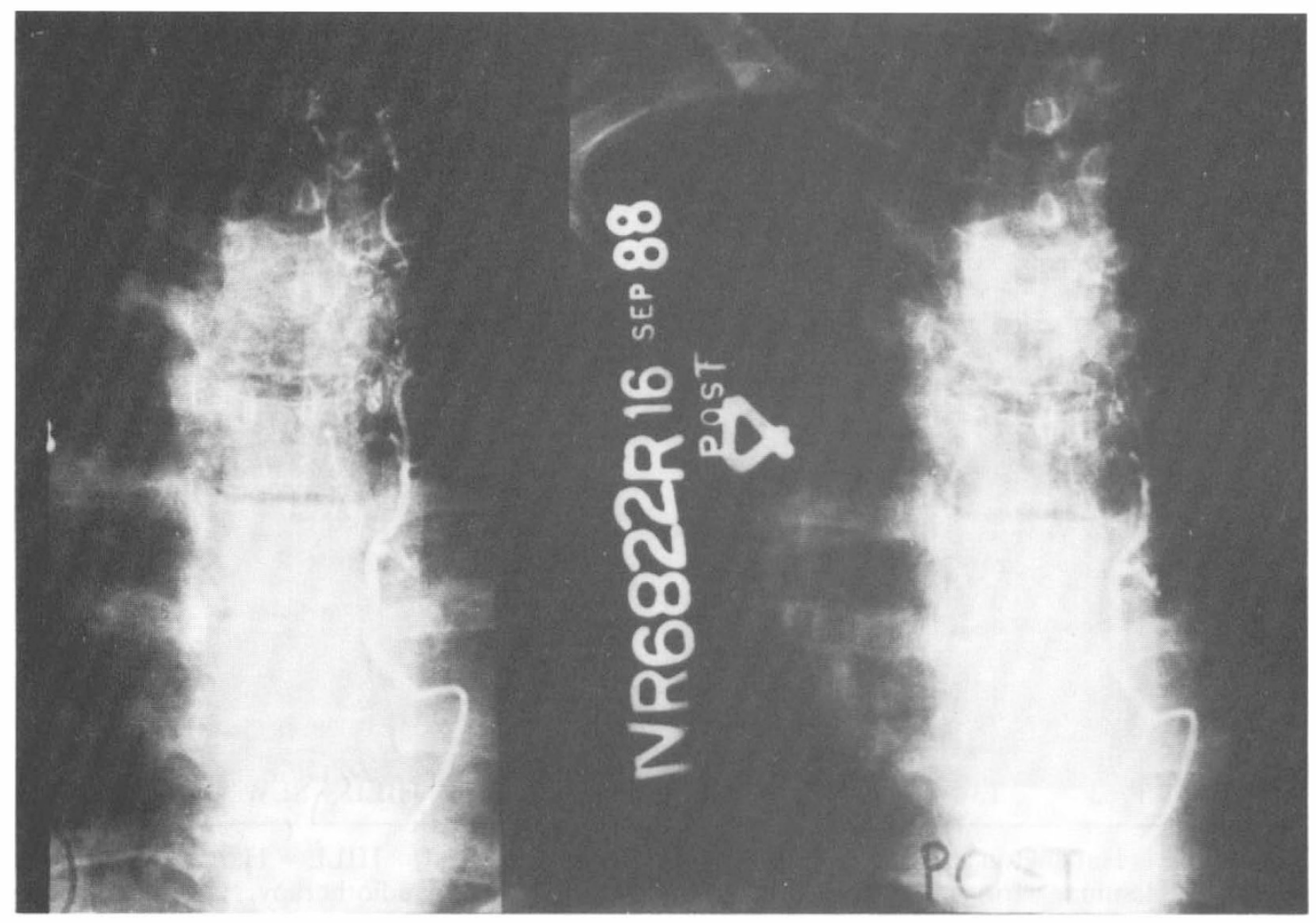

Figure 1a Pre and postembolisation pictures (Case no 8). 


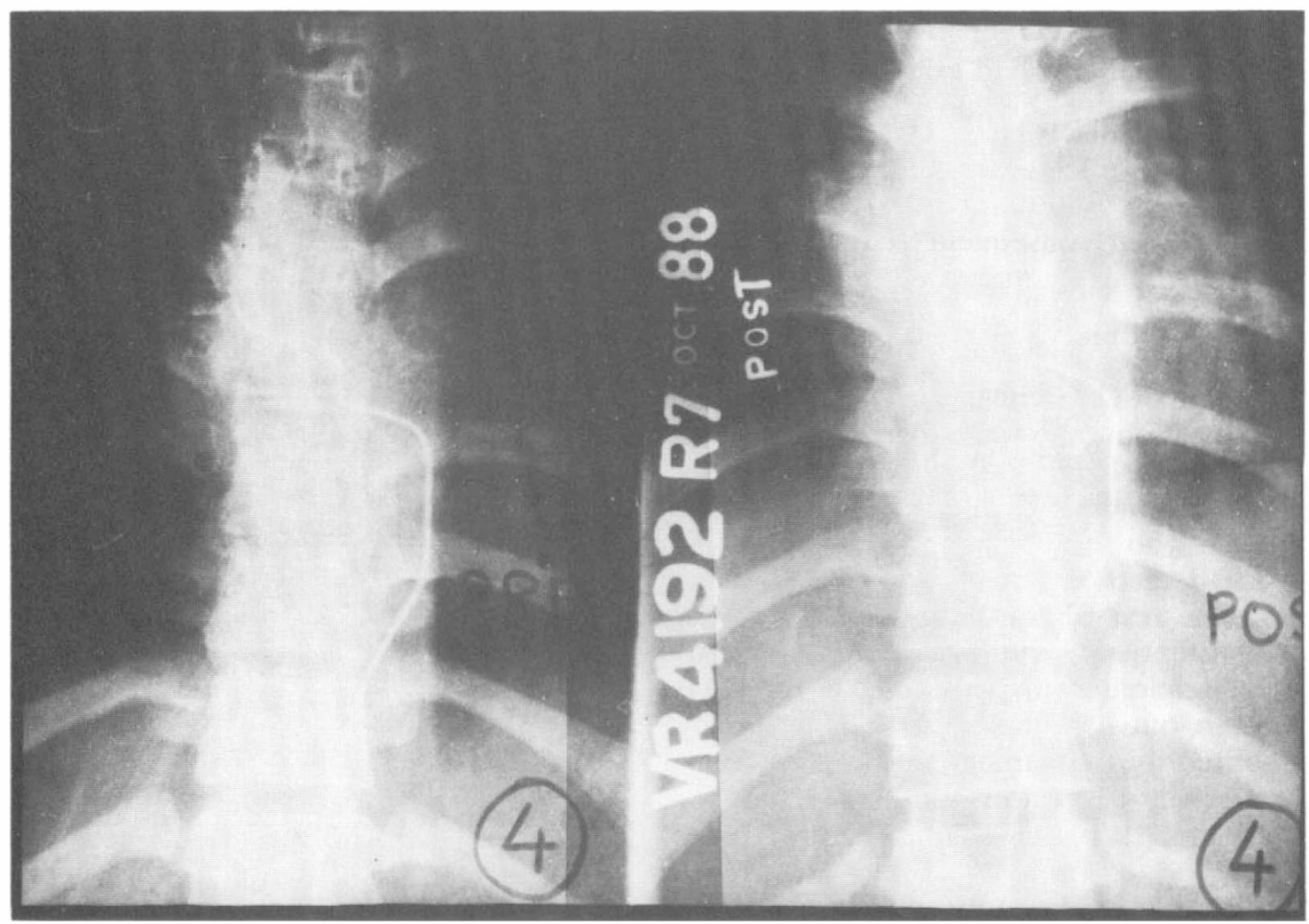

Figure 1b Pre and postembolisation pictures (Case no 7).

2 Transpendicular decompression. Patterson and Arbit ${ }^{13}$ have described a similar approach for the posterolateral removal of extruded thoracic discs. We have extended the use of this universal approach as we feel this offers adequate exposure for a global decompression (Fig 2). A same stage posterior stabilisation is also possible, with no additional

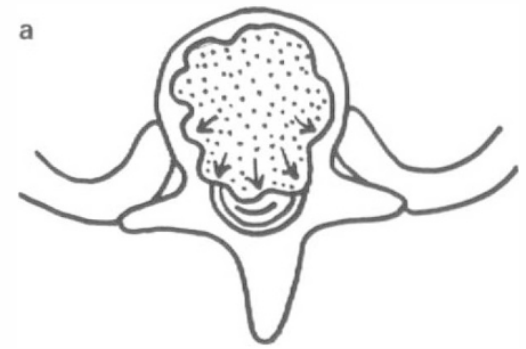

Figure 2a Schematic drawing showing metastatic deposit with extradural cord compression in the thoracic spine. exposure, thereby avoiding the morbidity associated with a thoracotomy.

3 Posterior instrumentation (Figs 3 and 4). As in most of the patients there is a vertebral compression failure and hence they will be stable in distraction. They are best stabilised by Harrington distraction rods. In one patient with a T3 lesion, the Harrington rods could not be placed optimally and hence a Hartshill rectangle with sublaminar wiring had to be used for stabilisation.

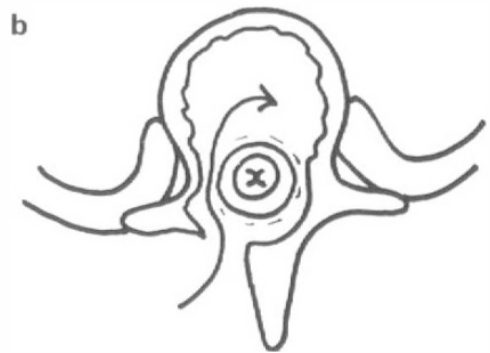

Figure 2b Transpedicular decompression. 


\section{Results}

All of our patients had excellent pain relief postoperatively. This aided the rehabilitation programme and transport to the Cancer Institute for back up chemotherapy and radiotherapy. All patients were required to sit up on the edge of the bed with a brace by the time of suture removal. The average follow up period in our study was 9.3 months, with a minimum of 4 months and a maximum of 18 months.

Two patients showed complete and 3 had partial neurological recovery as graded by Frankel's grading (Table I). All of those 5 patients who showed neurological recovery also had recovery of urinary bladder control. The rest of the patients were taught intermittent self catheterization prior to their discharge from the hospital.

Three out of 9 cases, though positively benefited by the surgery in the postoperative period, died within 4 months of surgery due to metastasis not related to the spine.

\section{Discussion}

On reviewing the present literature and analysing our patients, we felt that the problems in these cases were threefold.

1 Diagnosis. Knowing the exact histopathological diagnosis was mandatory to planning the future line of treatment. On this depends the schedule for chemotherapy and radiotherapy, the exact role of surgery and the ultimate prognostication of the lesion.

2 Spinal instability. This was responsible for the severe local and radiating pain, progressive deformity and continuing cord compression.

3 Neurological deficit. The motor, sensory and sphincter disturbances ultimately terminate in an untimely death without dignity.

Hence a rational way of management would include not only a biopsy and decompression procedure, but also sound spinal stabilisation.

Although occasional mention has been made of the necessity of decreasing the vascularity of these lesions, no definite protocol concerning preoperative embolisation of the metastatic lesions has been categorically mentioned. ${ }^{11}$ Preoperative embolisation helps to devascularise the tumour mass, and decrease the intraoperative blood loss and hence also reduces the operative time. The cell saver technique is not recommended for tumour surgery and hypotensive anaesthesia may be hazardous in these high risk cases especially with the patient in the prone position, with the added possibility of cord ischaemia. Since the introduction of this technique of preoperative embolisation we have been successful in minimising the blood loss to an average of 1.5 litres, and the operating time to an average of 3 hours. The bloodless field also helps in an adequate unhurried decompression and satisfactory stable internal fixation.

We prefer the transpedicular route for decompression because (1) it affords a route for adequate global decompression of the anterior, lateral and posterior tumour cuff, which is not possible by a transthoracic route; (2) a same stage posterior stabilisation is possible; and (3) it avoids all of the chest complications of a thoracotomy approach in these critically ill patients.

We feel that the Harrington distraction rods provide the best form of stabilisation because most of these pathological fractures are compression failures and hence are stable in distraction. The ease and rapidity of instrumentation is a distinct advantage. Since the thoracic spine is relatively immobile a fixation which spans 2 or 3 levels above and below does not markedly alter the overall functional end result.

Bone grafts for stabilisation have to be discouraged for patients who are due to have irradiation. In addition to the overall poor healing potential, bone grafts have a distinct risk of being devitalised by the high doses of radiotherapy.

Bone cement for stabilisation, although best suited for use under compression, has a risk of loosening and of infection. Moreover thermal damage to the thoracic spinal cord is a distinct possible complication. Its use has been recommended only in patients with a life expectancy of one year or less. ${ }^{14}$

We feel that the duration of spinal cord compression is an important factor in re- 
a

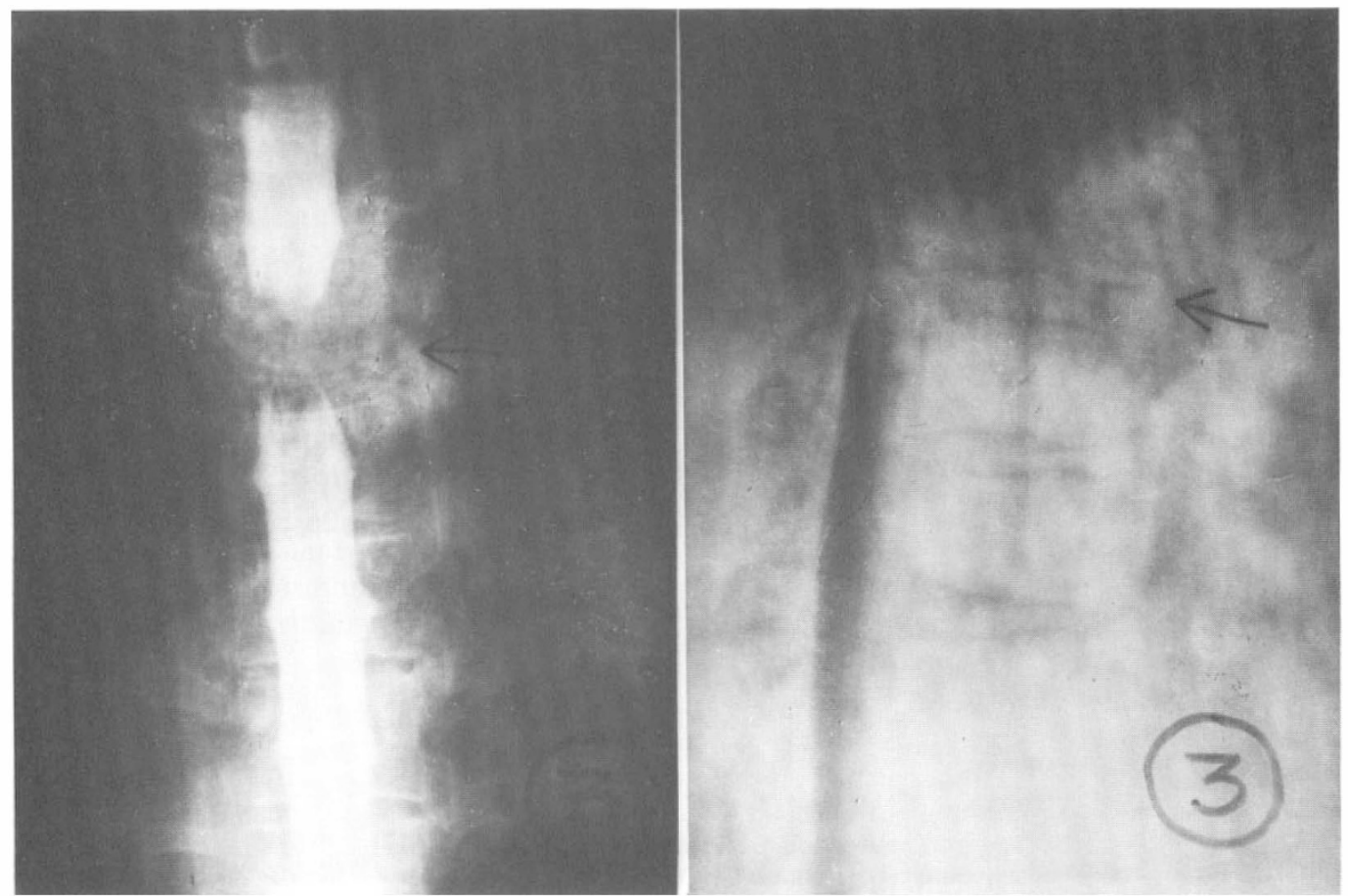

b

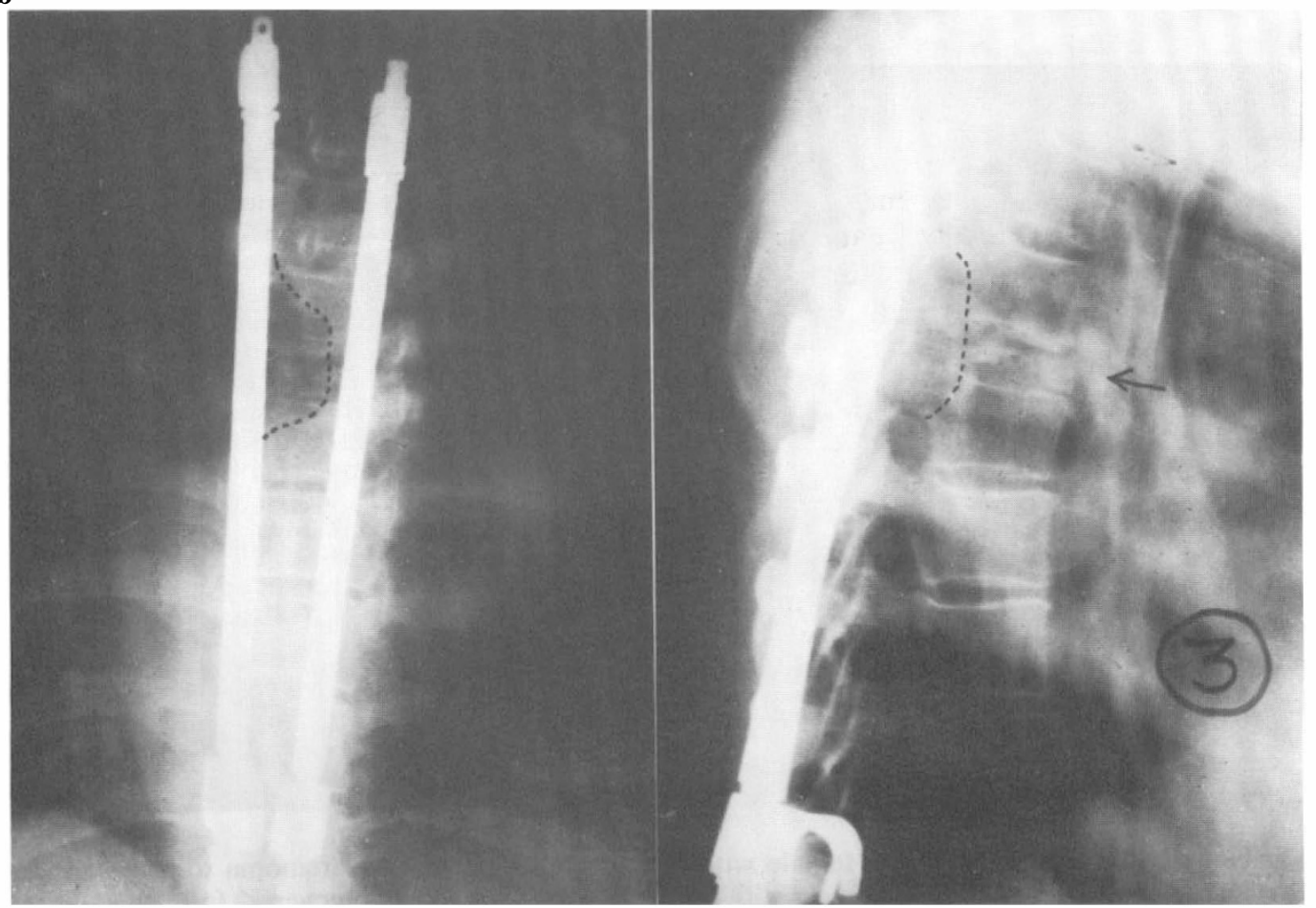

Figure 3 Case no 7: 48 year old female with metastasis from Ca breast to T4 vertebra. Myelogram revealed a total block at T8 level. Patient completely recovered following decompression stabilisation and back up chemotherapy and radiotherapy. (a) preoperative, (b) postoperative. 
a

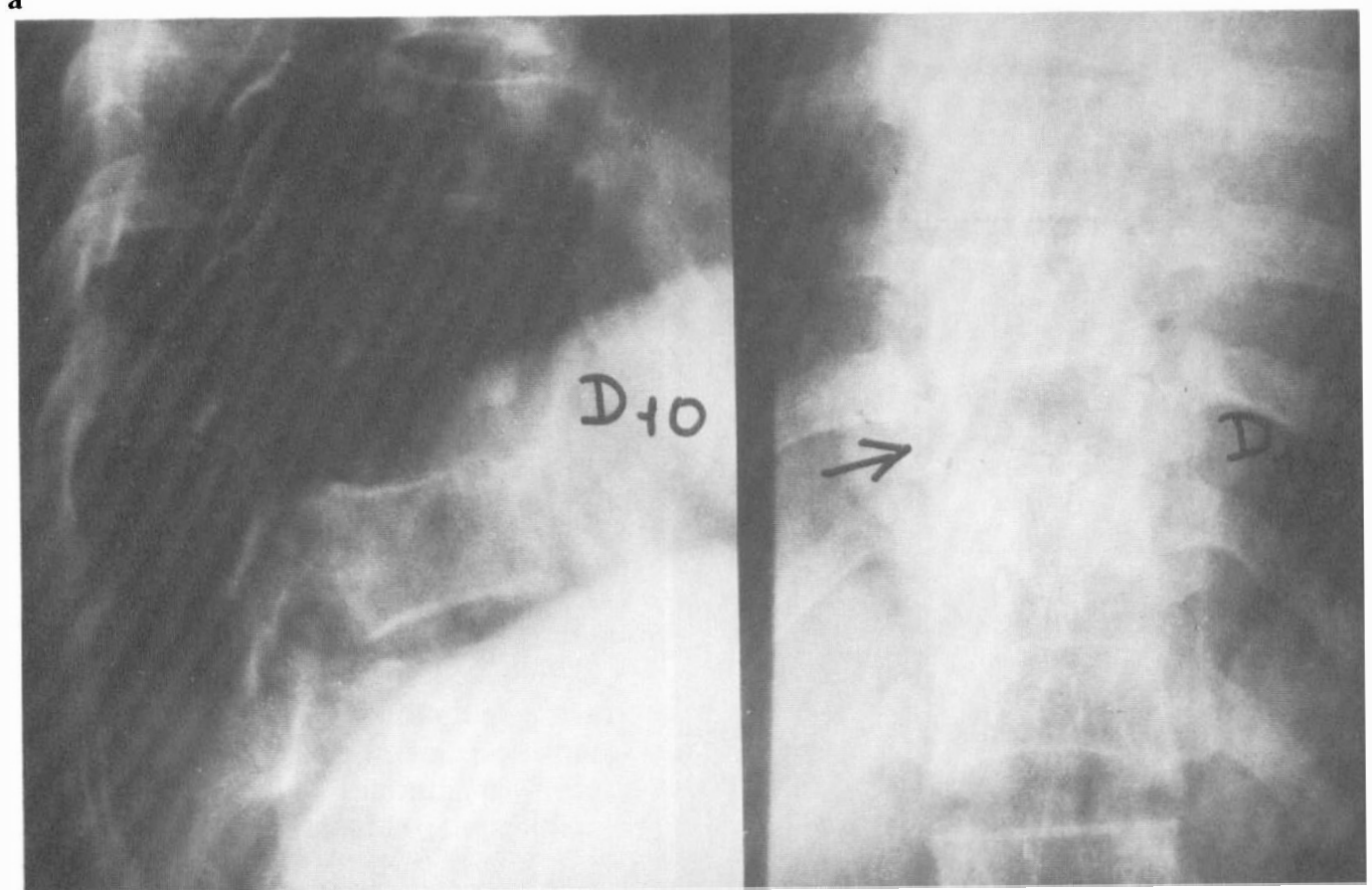

b

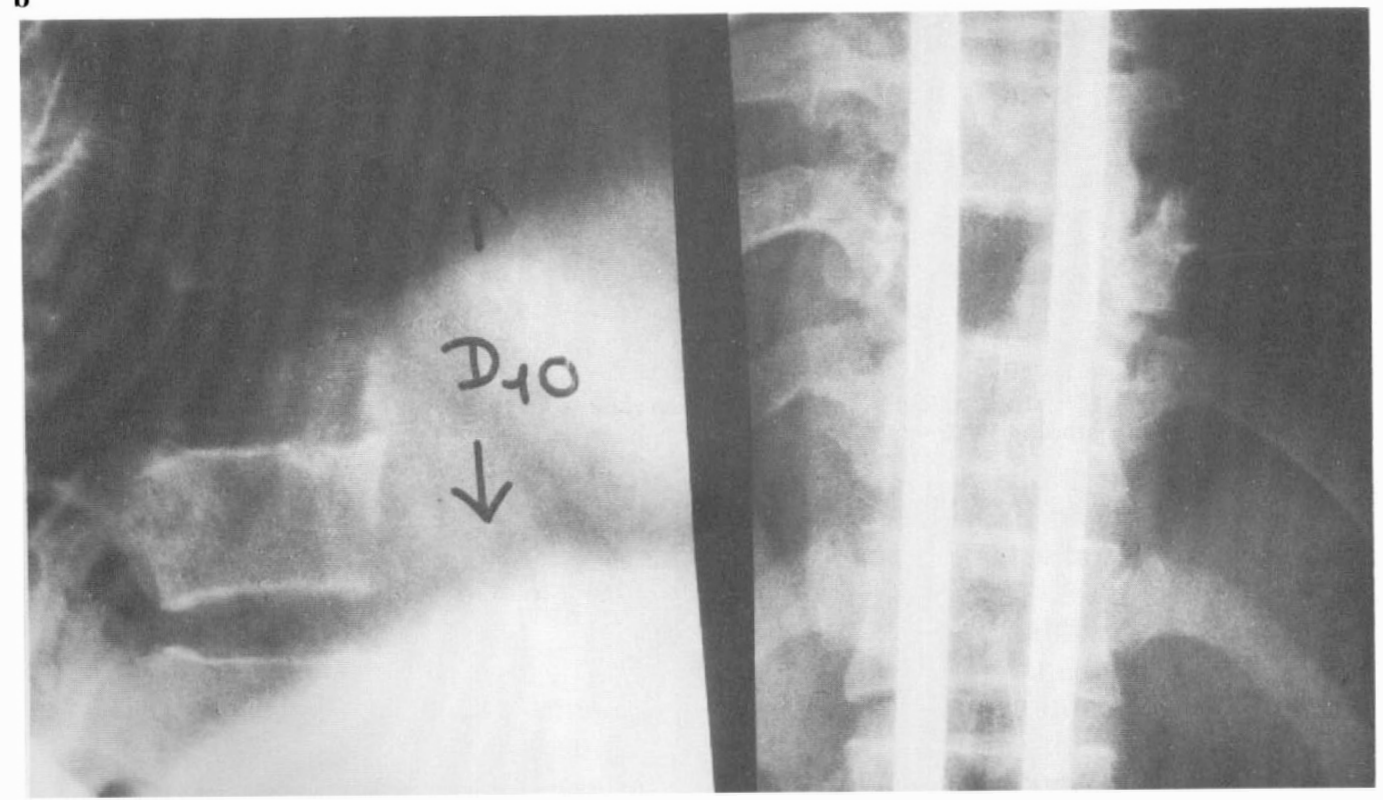

Figure 4 Case no. 3: 55 year old female with metastasis from thyroid carcinoma to T10 vertebra. Myelogram revealed a total block at T10 level. Patient completely recovered following decompression, stabilisation and back up chemotherapy and radiotherapy. (a) preoperative, (b) postoperative. 
covery. Except for one case of metastasis from a rhabdomyosarcoma where the duration of cord compression was 16 weeks, in the other patients, who showed either partial or complete recovery, the duration of cord compression ranged from 3-8 weeks. Hence we feel that an earlier referral from a peripheral centre to a central institute would greatly benefit the patient.

It was also noticed that there is no correlation between the initial grading of the paraparesis and subsequent recovery (as demonstrated in case no 7 and case no 1).

We feel that neurological recovery is not the primary aim of our approach. Improving the quality of life and facilitating the management of the primary malignant disease process are the primary aims of this treatment protocol.

\section{Conclusion}

From our brief but significant experience, we feel strongly that this new approach of aggressively confronting these lesions in selected cases is rewarding and encouraging and we hope to continue to offer it as a palliative modality to these unfortunate patients.

\section{Acknowledgements}

We thank Dr RS Dhir, Professor \& Head, Department of Orthopaedics, SDB Orthopaedic Centre, KEM Hospital, Bombay, for allowing us to evaluate, manage and study these cases and Dr (Mrs) PM Pai, Dean, KEM Hospital and Seth GS Medical College, Bombay, India for permission to report hospital data.

\section{References}

1 Siegal T, Tiqva P, Siegal T (1985) Vertebral body resection for epidural compression by malignant tumours, results of 47 consecutive operative procedures. J Bone Joint Surg 67A: 375- 382.

2 Dunn RC Jr, Kelly WA, Wons RNW, Howe JF (1980) Spinal epidural neoplasia - a 15 year review of the results of surgical therapy. J Neurosug 52: 47-51.

3 Gilbert HA, Kagan AR, Nussbaum H et al (1977) Evaluation of radiation therapy for bone metastasis: pain relief and quality of life. Am J Roentgenol 129: 1095-1096.

4 Schocker JD, Brady LW (1982) Radiation therapy for bone metastasis. Clin Orthop 169: 38-43.

5 Marshall LF, Langfitt TW (1977) Combined therapy for metastatic extradural tumours of the spine. Cancer 40: 2067- 2070.

6 Gilbert RW, Kim JH, Posner JB (1978) Epidural spinal and compression from metastatic tumour: diagnosis and treatment. Ann Neurol 3: 40-41.

7 Young RF, Post EM, King GA (1980) Treatment of spinal epidural metastasis; randomized prospective comparison of laminectomy and radiotherapy. J Neurosurg 53: 741-748.

8 Hall AJ, Mackay NNS (1973) The results of laminectomy for compression of the cord of cauda equina by extradural malignant tumour. J Bone Joint Surg 55B: 497-505.

9 Flatley JJ, Anderson MM, Anast GT (1984) Spinal instability due to malignant disease: treatment by segmental spinal stabilization. J Bone Joint Surg 66A: 47-52.

10 Findlay GFG (1984) Adverse effects of the management of malignant spinal cord compression. $J$ Neurol, Neurosurg Psychiatry 47: 761-768.

11 Harrington KD (1981) The use of methylmethacrylate for vertebral body replacement and anterior stabilization of pathological fracture - dislocation of the spine due to metastatic malignant disease. J Bone Joint Surg 63A: $36-46$.

12 Boland PJ, Lene JM, Sundersen N (1982) Metastatic disease of the spine. Clin Orthop 169: 95-102.

13 Patterson RH Jr, Arbit E (1978) A surgical approach through the pedicle to protruded thoracic disc. $J$ Neurosurg 48: 760-764.

14 Kostuik J, Enrico T, Gleason T (1988) Spinal stabilization of vertebral column tumours. Spine 13 (3): 250-256 